\title{
Effect of limb cooling on peripheral and global oxygen consumption in neonates
}

\author{
I A-A Hassan, Y A Wickramasinghe, S A Spencer
}

Arch Dis Child Fetal Neonatal Ed 2003;88:F139-F142

See end of article for authors' affiliations

......................

Correspondence to: Dr Spencer, Neonatal Unit, Maternity Building, North

Staffordshire Hospital (City General), Newcastle Road, Stoke on Trent ST4 6QG,

UK; andy.spencer@

nstaffsh.wmids.nhs.uk

Accepted 11 July 2002

\begin{abstract}
Aim: To evaluate peripheral oxygen consumption $\left(\mathrm{VO}_{2}\right)$ measurements using near infrared spectroscopy (NIRS) with arterial occlusion in healthy term neonates by studying the effect of limb cooling on peripheral and global $\mathrm{VO}_{2}$.

Subjects and methods: Twenty two healthy term neonates were studied. Peripheral $\mathrm{VO}_{2}$ was measured by NIRS using arterial occlusion and measurement of the oxyhaemoglobin $\left(\mathrm{HbO}_{2}\right)$ decrement slope. Global $\mathrm{VO}_{2}$ was measured by open circuit calorimetry. Global and peripheral $\mathrm{VO}_{2}$ was measured in each neonate before and after limb cooling.

Results: In 10 neonates, a fall in forearm temperature of $2.2^{\circ} \mathrm{C}$ (mild cooling) decreased forearm $\mathrm{VO}_{2}$ by $19.6 \%(\mathrm{p}<0.01)$. Global $\mathrm{VO}_{2}$ did not change. In 12 neonates, a fall in forearm temperature of $4^{\circ} \mathrm{C}$ (moderate cooling) decreased forearm $\mathrm{VO}_{2}$ by $34.7 \%(\mathrm{p}<0.01)$. Global $\mathrm{VO}_{2}$ increased by $17.6 \%$ $(\mathrm{p}<0.05)$.

Conclusions: The NIRS arterial occlusion method is able to measure changes in peripheral $\mathrm{VO}_{2}$ induced by limb cooling. The changes are more pronounced with moderate limb cooling when a concomitant rise in global $\mathrm{VO}_{2}$ is observed. Change in peripheral temperature must be taken into consideration in the interpretation of peripheral $\mathrm{VO}_{2}$ measurements in neonates.
\end{abstract}

$\mathrm{E}$ arly in circulatory compromise, compensatory mechanisms maintain oxygen delivery to vital organs, such as the brain and heart, through redistribution of blood flow away from the periphery. This will give rise to reduced peripheral perfusion, thereby limiting oxygen uptake by these areas. Studies during critical care in adults, using invasive oxygen electrodes, suggest that hypoxic changes in skeletal muscle may be observed before there is a significant change in blood pressure. ${ }^{1}$ Therefore a method for assessment of peripheral oxygen consumption in neonates may give an early warning of the need for circulatory support during critical care. ${ }^{2}$ Cerebral ischaemic lesions are still an important cause of neurodevelopmental problems in preterm infants. ${ }^{3}$ There is evidence that prevention of hypotension is important in the prevention of these lesions, ${ }^{4-6}$ and the British Association of Perinatal Medicine guidelines ${ }^{7}$ promote the maintenance of mean arterial pressure above predefined limits. Unfortunately this strategy has not been effective in preventing the development of cerebral ischaemic lesions. The cause of this white matter damage is almost certainly multifactorial, with contributions from antenatal infection (chorioamnionitis) ${ }^{89}$ and hypocapnia. ${ }^{10}{ }^{11}$ Nevertheless it is possible that improved management of the circulation, particularly in the first 48 hours of life, may improve brain perfusion and lead to improved outcomes for these babies.

Previously we reported a non-invasive method for measurement of peripheral oxygen consumption $\left(\mathrm{VO}_{2}\right)$ in neonates using near infrared spectroscopy (NIRS) with arterial occlusion. ${ }^{12}$ Before assessing this technique during critical care, it was necessary to understand how changes in the external environment may affect the measurements obtained. Changes in environmental temperature may have a profound effect on both metabolic rate ${ }^{13}$ and limb temperature. Consequently studies were undertaken in healthy term infants to examine the effects of interventions that were designed to mainly affect either limb temperature (limb cooling) or global metabolic rate. This paper describes the results of the first of these two interventions.

\section{AIM}

The aim of this study was to determine the effect of mild and moderate limb cooling on peripheral $\mathrm{VO}_{2}$ using NIRS with arterial occlusion, and global $\mathrm{VO}_{2}$ using open circuit calorimetry, in healthy term neonates. A fall in peripheral $\mathrm{Vo}_{2}$ with little change in global $\mathrm{VO}_{2}$ was expected.

\section{METHODS}

\section{Subjects}

Healthy term infants during the first few days of life were recruited on the postnatal wards of North Staffordshire Hospital. None were receiving medication or supplemental oxygen. A pragmatic approach was taken to sample size, with this set as a minimum of 10 successful studies, as no data were available to perform statistical power calculations.

\section{Consent}

The study and the information leaflet given to parents were approved by North Staffordshire research ethics committee. Parental written informed consent was obtained before the study.

\section{Measurements}

\section{Peripheral $\mathrm{VO}_{2}$}

Peripheral $\mathrm{VO}_{2}$ was measured using NIRS and arterial occlusion as previously described and illustrated. ${ }^{12}$

In brief, NIRS can be used to monitor changes in concentrations of oxygenated haemoglobin $\left(\mathrm{HbO}_{2}\right)$ and total haemoglobin (HbT). When arterial occlusion is performed, there is an abrupt decrease in $\mathrm{HbO}_{2}$, which is entirely due to oxygen utilisation, provided that no blood enters or leaves the limb. Thus peripheral $\mathrm{VO}_{2}$ can be calculated by measurement of the slope of $\mathrm{HbO}_{2}$ decrement provided that $\mathrm{HbT}$ does not change. Not every occlusion is satisfactory; movement in

Abbreviations: $\mathrm{VO}_{2}$, oxygen consumption; $\mathrm{NIRS}$, near infrared spectroscopy; $\mathrm{HbO}_{2}$, oxygenated haemoglobin; $\mathrm{HbT}$, total haemoglobin; $\mathrm{Cl}$, confidence interval 
Table 1 Details of neonates studied

\begin{tabular}{lll}
\hline & Mild cooling & Moderate cooling \\
\hline Number in study group & 10 & 12 \\
Gestational age (weeks) & $38(3)$ & $40(1)$ \\
Mode of delivery & CS 3, VD 7 & CS 11, VD 1 \\
Birth weight (g) & $3.5(2.7-4.0)$ & $3.6(3.0-4.7)$ \\
Postnatal age (days) & $2(1-6)$ & $2(1-4)$ \\
F:M & $6: 4$ & $9: 3$ \\
\hline
\end{tabular}

Values are mean (SD) or median (range).

$C S$, Caesarean section; VD, vaginal delivery; $F$, female; $M$, male.

particular may cause problems. Therefore in our previous work, criteria were defined for accepting an occlusion as suitable for further analysis. Only occlusions meeting these predefined criteria ${ }^{12}$ have been included in the results. For an occlusion to pass, there has to be an abrupt decrease in $\mathrm{HbO}_{2}$ and increase in $\mathrm{Hb}$ immediately after the occlusion. The $\mathrm{HbT}$ trace also has to remain stable, with a maximum permitted change of $<10 \%$ of the change in $\mathrm{HbO}_{2}$. The coefficient of variation for the measurement $\mathrm{VO}_{2}$ is $6.6 \%$.

\section{NIRS units}

The basic uncorrected units for $\mathrm{HbO}_{2}$ are mM.cm. $\mathrm{VO}_{2}$ is calculated using the rate of change of $\mathrm{HbO}_{2}$ signal during arterial occlusion and is expressed as $\mathrm{mM} \mathrm{HbO}_{2} \cdot \mathrm{cm} / \mathrm{min}$. By taking into account the molecular ratio of $\mathrm{Hb}$ to $\mathrm{O}_{2}$, which is $1: 4, \mathrm{VO}_{2}$ can be expressed as $\mathrm{mM} \mathrm{O}_{2} \cdot \mathrm{cm} / \mathrm{min}$. These units have been used because no assumptions about differential path length factor are required. Thus comparisons between babies is valid. Other studies have used $\mu \mathrm{mol} \mathrm{O}_{2} / 100 \mathrm{ml} / \mathrm{min}^{2}{ }^{2}$ which requires a path length correction factor, which is assumed to be a constant of 3.59. For a distance of $3 \mathrm{~cm}$ between probes, the conversion factor is $100 /(3.59 \times 3)$, which is 9.3 . Thus $\mu \mathrm{mol} \mathrm{O}_{2} / 100$ $\mathrm{ml} / \mathrm{min}=9.3 \times \mathrm{mM} \mathrm{O}_{2} \cdot \mathrm{cm} / \mathrm{min}$. (The convention in NIRS is to use mM.cm to show that the value has not been divided by the path length correction factor.)

\section{Global $\mathrm{VO}_{2}$}

This was measured using open circuit calorimetry (Morgan Ltd, Gillingham, Kent, UK).$^{14}$ The technique was modified to use a facemask rather than an incubator for gas collection. ${ }^{15}$

Briefly described, the infant's expired air was continuously drawn through a face mask (cushion flex infant mask; Intrasurgical, Wokingham, Berkshire, UK) held in front of the infant's nose and mouth at a constant flow rate of 2-3 litres/min.

Room air was also continuously sampled and the oxygen concentration of both the mixed expired air and room air was measured continuously by open circuit calorimetry.

Global $\mathrm{VO}_{2}$ was calculated using the formula:

$$
\mathrm{VO}_{2}=\mathrm{Q}\left(\mathrm{FIO}_{2}-\mathrm{FEO}_{2}\right)
$$

where $\mathrm{Q}=$ flow through the system, $\mathrm{FIO}_{2}=$ fractional concentration of oxygen in inspired air (room air), and $\mathrm{FEO}_{2}=$ fractional concentration of oxygen in expired air (infant's expired air). Global $\mathrm{Vo}_{2}$ results were expressed as $\mathrm{ml}$ $\mathrm{O}_{2} / \mathrm{kg} / \mathrm{min}$.

\section{Skin temperature}

Forearm and abdominal skin temperatures were measured with a digital thermometer (Libra Medical), which had previously been calibrated against a mercury in glass thermometer. The skin probe was placed on the dorsal aspect of the forearm opposite the NIRS optode holders. A second temperature probe placed on the upper abdomen continuously measured abdominal skin temperature.

\section{Protocol}

The same researcher performed measurements on all neonates. They were all carried out at the same time of day (11 am), 1-1.5 hours after a feed and in the same environment (postnatal ward). The neonate was placed fully clothed in his/ her cot. Clothing was then partially removed for the purpose of placing temperature probes and NIRS probes in position, and to place an appropriately sized neonatal blood pressure cuff around the upper arm. The distance between the transmitting and receiving optical probes was $3 \mathrm{~cm}$. When the baby had settled, the measurements were started.

Initial measurements of global $\mathrm{VO}_{2}$, forearm and abdominal skin temperatures, and up to three successful measurements of forearm $\mathrm{VO}_{2}$ were performed on each neonate. In 10 neonates, the forearm was then cooled by exposure of the forearm to room air for 15-20 minutes (mild limb cooling). In the other 12 neonates, the forearm was cooled by the application of cotton wool soaked in tepid water (moderate limb cooling). All the measurements were then repeated up to three times. The distance between the transmitting and receiving optical probes was $3 \mathrm{~cm}$.

\section{Data analysis}

The results of global and peripheral $\mathrm{VO}_{2}$ and skin temperatures for all subjects are presented as means with 95\% confidence intervals (95\% CI). Where more than one successful measurement of peripheral $\mathrm{VO}_{2}$ was obtained in a subject, before or after the intervention, then the mean value was used. Paired $t$ tests (before and after) were used to determine the significance of observed changes. The level of significance was set at 0.05 .

\section{RESULTS}

Twenty two neonates were included and completed the whole study.

\section{Mild limb cooling}

Subjects

Table 1 gives the details of the 10 neonates studied.

\begin{tabular}{|c|c|c|c|c|c|}
\hline & Before & After & Difference & Change (\%) & $\mathrm{p}$ Value \\
\hline Forearm skin temperature $\left({ }^{\circ} \mathrm{C}\right)$ & 33 & 30.8 & -2.2 & \multirow[t]{2}{*}{-6.7} & \multirow[t]{2}{*}{0.001} \\
\hline $95 \% \mathrm{Cl}$ & 31.4 to 34.6 & 29.3 to 32.3 & -3.2 to -1.2 & & \\
\hline Abdominal skin temperature $\left({ }^{\circ} \mathrm{C}\right)$ & 36.8 & 37 & +0.2 & \multirow[t]{2}{*}{+0.5} & \multirow[t]{2}{*}{ NS } \\
\hline $95 \% \mathrm{Cl}$ & 36.2 to 37.4 & 36.6 to 37.4 & -0.38 to +0.14 & & \\
\hline Peripheral $\mathrm{VO}_{2}\left(\mathrm{mM} \mathrm{O}_{2} \cdot \mathrm{cm} / \mathrm{min}\right)$ & 1.38 & 1.11 & -0.27 & \multirow[t]{2}{*}{-19.6} & \multirow[t]{2}{*}{0.005} \\
\hline $95 \% \mathrm{Cl}$ & 1.10 to 1.66 & 0.87 to 1.35 & -0.44 to -0.11 & & \\
\hline Global Vo $\mathrm{O}_{2}(\mathrm{ml} / \mathrm{kg} / \mathrm{min})$ & 9.95 & 9.86 & -0.09 & \multirow[t]{2}{*}{-0.9} & \multirow[t]{2}{*}{ NS } \\
\hline $95 \% \mathrm{Cl}$ & 8.91 to 10.99 & 7.82 to 11.9 & -1.91 to +2.09 & & \\
\hline
\end{tabular}


Table 3 Results of moderate limb cooling

\begin{tabular}{|c|c|c|c|c|c|}
\hline & Before & After & Difference & Change (\%) & p Value \\
\hline $\begin{array}{l}\text { Forearm skin temperature }\left({ }^{\circ} \mathrm{C}\right) \\
95 \% \mathrm{Cl}\end{array}$ & $\begin{array}{l}33.2 \\
32.4 \text { to } 34\end{array}$ & $\begin{array}{l}29.2 \\
28.7 \text { to } 29.7\end{array}$ & $\begin{array}{l}-4 \\
-3.4 \text { to }-4.6\end{array}$ & -12 & 0.001 \\
\hline $\begin{array}{l}\text { Abdominal skin temperature }\left({ }^{\circ} \mathrm{C}\right) \\
95 \% \mathrm{Cl}\end{array}$ & $\begin{array}{l}36.7 \\
36.3 \text { to } 37.1\end{array}$ & $\begin{array}{l}36.5 \\
36.0 \text { to } 37.0\end{array}$ & $\begin{array}{l}-0.2 \\
-0.2 \text { to }+0.5\end{array}$ & -0.5 & N/S \\
\hline $\begin{array}{l}\text { Peripheral } \mathrm{VO}_{2}\left(\mathrm{mM} \mathrm{O}_{2} \cdot \mathrm{cm} / \mathrm{min}\right) \\
95 \% \mathrm{Cl}\end{array}$ & $\begin{array}{l}1.01 \\
0.78 \text { to } 1.24\end{array}$ & $\begin{array}{l}0.66 \\
0.53 \text { to } 0.79\end{array}$ & $\begin{array}{l}-0.35 \\
-0.12 \text { to }-0.58\end{array}$ & -34.7 & 0.01 \\
\hline $\begin{array}{l}\text { Global Vo }(\mathrm{ml} / \mathrm{kg} / \mathrm{min}) \\
95 \% \mathrm{Cl}\end{array}$ & $\begin{array}{l}8.8 \\
8.02 \text { to } 9.58\end{array}$ & $\begin{array}{l}10.35 \\
9.43 \text { to } 1.27\end{array}$ & $\begin{array}{l}+1.55 \\
0.47 \text { to } 2.6\end{array}$ & +17.6 & 0.01 \\
\hline
\end{tabular}

Temperature and $\mathrm{VO}_{2}$

The mean (SD) room temperature was $28.5(1.7)^{\circ} \mathrm{C}$ throughout the studies.

Table 2 shows the results of mild limb cooling; they can be summarised as follows.

- Mild limb cooling led to a mean fall in peripheral skin temperature of just over $2^{\circ} \mathrm{C}$.

- Abdominal skin temperature did not change significantly.

- There was a highly significant fall in peripheral $\mathrm{VO}_{2}$.

- There was no significant change in global $\mathrm{Vo}_{2}$.

\section{Moderate limb cooling}

Subjects

Table 1 gives details of the 12 neonates studied.

Temperature and $\mathrm{VO}_{2}$

The mean room temperature was $28.5(1.7)^{\circ} \mathrm{C}$ throughout the studies.

Table 3 gives the results of mild limb cooling; they can be summarised as follows.

- Moderate limb cooling led to a mean fall in peripheral skin temperature of $4^{\circ} \mathrm{C}$.

- Abdominal skin temperature did not change significantly.

- There was a highly significant fall in peripheral $\mathrm{VO}_{2}$.

- There was a significant increase in global $\mathrm{Vo}_{2}$.

\section{DISCUSSION}

These studies show that, subject to the selection criteria stated in the measurement section, arterial occlusion and NIRS detects the expected fall in oxygen uptake resulting from limb cooling. The effect is more pronounced when the decrease in limb temperature is greater. Mild limb cooling does not appear to represent a sufficient cold stress to significantly increase global metabolic rate. This is in line with previous studies in which a fall of $1.5^{\circ} \mathrm{C}$ was found to cause sleep disturbance but no increase in global $\mathrm{VO}_{2} .{ }^{16}{ }^{17}$ Moderate cooling on the other hand did elicit a global response, even though abdominal skin temperature was not significantly affected. This response may have been elicited as a result of sympathetic stimulation from the application of tepid water, which is not only a cold stimulus but may also cause mild discomfort. Alternatively, the heat loss from the limb may have been sufficient to cause the neonate to move out of the thermal neutral zone, so that an increase in global metabolic rate was required to maintain body temperature. The rise in global metabolic rate did not counteract the effect of peripheral cooling; further studies are required to determine whether peripheral $\mathrm{VO}_{2}$ measurement is sensitive to change in global metabolic rate.

In this study, data are presented using the same units as in our previous study. No assumptions on differential path length factor are required, therefore comparisons between babies are valid. Others have assumed that differential path length is near enough a constant to allow comparisons between babies using a venous occlusion technique. ${ }^{2}$ Our own work comparing venous and arterial methods suggests a poor correlation, with values about $50 \%$ higher using the venous technique. ${ }^{12}$ In normotensive sick preterm infants, the mean $\mathrm{Vo}_{2}$ has been reported as $23.9 \mu \mathrm{mol} / 100 \mathrm{ml} / \mathrm{min}$ using the venous technique. ${ }^{2}$ The mean value obtained in healthy term infants before limb cooling translates to 12.8 and $9.4 \mu \mathrm{mol} / 100$ $\mathrm{ml} / \mathrm{min}$ for the mild and moderate limb cooling studies respectively. Clearly, healthy term and sick preterm babies are not comparable. Unfortunately comparable data on healthy term infants are not available, apart from our previous validation work. ${ }^{12}$ In this study the results for arterial occlusion translates to $10.4 \mu \mathrm{mol} / 100 \mathrm{ml} / \mathrm{min}$ and for venous occlusion translates to $14.8 \mu \mathrm{mol} / 100 \mathrm{ml} / \mathrm{min}$.

The findings of this study have two important implications. Firstly, they lend support to the hypothesis that changes in peripheral $\mathrm{VO}_{2}$ can be assessed using this method. Unfortunately there is no ideal non-invasive method available, with which NIRS occlusion techniques can be validated. Therefore indirect evidence is the best that can be obtained.

Secondly, if this technique is to be used to assess the need for circulatory support, this study shows the importance of monitoring peripheral temperature. It has to be recognised that reduced peripheral perfusion may cause a fall in skin temperature, which may make the results harder to interpret. ${ }^{18}$ However, vasomotor response to cooling is less developed in the preterm infant, ${ }^{18}{ }^{19}$ especially in the very small sick infant. Thus interpretation of results may be straightforward in this group, particularly in the controlled environment of a humidified incubator.

\section{Conclusion}

NIRS with arterial occlusion can be used to monitor peripheral $\mathrm{VO}_{2}$. This measurement is very sensitive to changes in limb temperature in term infants.

Authors' affiliations

I A-A Hassan, S A Spencer, Neonatal Unit, City General Hospital, Stoke on Trent, UK

Y A Wickramasinghe, Centre for Science and Technology in Medicine, University of Keele, UK

\section{REFERENCES}

1 Beerthuizen GI, Goris RJ, Kreuzer FJ. Skeletal muscle $\mathrm{PO}_{2}$ during imminent shock. Arch Emerg Med 1989;6:172-82.

2 Wardle SP, Yoxall CW, Weindling AM. Peripheral oxygenation in hypotensive preterm babies. Pediatr Res 1999;45:343-9.

3 Pierrat V, Duquennoy C, van Haastert IC, et al. Ultrasound diagnosis and neurodevelopmental outcome of localised and extensive cystic periventricular leucomalacia. Arch Dis Child Fetal Neonatal Ed 2001;84:F151-6.

4 Miall-Allen VM, de Vries LS, Whitelaw AG. Mean arterial blood pressure and neonatal cerebral lesions. Arch Dis Child 1987;62:1068-9. 
5 Bada HS, Korones SB, Perry EH, et al. Mean arterial blood pressure changes in premature infants and those at risk for intraventricular hemorrhage. J Pediatr 1990;117:607-14.

6 Watkins AM, West CR, Cooke RW. Blood pressure and cerebral haemorrhage and ischaemia in very low birthweight infants. Early Hum Dev 1989:19:103-10.

7 Development of audit measures and guidelines for good practice in the management of neonatal respiratory distress syndrome. Report of a Join Working Group of the British Association of Perinatal Medicine and the Research Unit of the Royal College of Physicians. Arch Dis Child 1992:67:1221-7.

8 Saliba E, Marret $S$. Cerebral white matter damage in the preterm infant: pathophysiology and risk factors. Semin Neonatol 2001;6:121-33.

9 Perlman JM, Risser R, Broyles RS. Bilateral cystic periventricular leukomalacia in the premature infant: associated risk factors. Pediatrics 1996:97:822-7.

10 Ambalavanan N, Carlo WA. Hypocapnia and hypercapnia in respiratory management of newborn infants. Clin Perinatol 2001;28:517-31.

11 Wiswell TE, Graziani L, Kornhauser MS, et al. Effects of hypocarbia on the development of cystic periventricular leukomalacia in premature infants treated with high-frequency jet ventilation. Pediatrics 1996;98:918-24.
12 Hassan IA Spencer SA, Wickramasinghe YA et al. Measurement of peripheral oxygen utilisation in neonates using near infrared spectroscopy: comparison between arterial and venous occlusion methods. Early Hum Dev 2000;57:21 1-24.

13 Hey EN. The relation between environmental temperature and oxygen consumption in the newborn baby. J Physiol (Lond) 1969;200:589-603

14 Handley JC, Spencer SA, Rakowski S, et al. Critical appraisal and further development of the methodology for open circuit calorimetry in neonates. Early Hum Dev 1991;26:167-76.

15 Smales OR. Simple method for measuring oxygen consumption in babies. Arch Dis Child 1978:53:53-7.

16 Bach V, Telliez F, Zoccoli G, et al. Interindividual differences in the thermoregulatory response to cool exposure in sleeping neonates. Eur $J$ Appl Physiol 2000;81:455-62.

17 Telliez F, Bach V, Krim G, et al. Consequences of a small decrease of air temperature from thermal equilibrium on thermoregulation in sleeping neonates. Med Biol Eng Comput 1997;35:516-20.

18 Lyon AJ, Pikaar ME, Badger P, et al. Temperature control in very low birthweight infants during first five days of life. Arch Dis Child Fetal Neonatal Ed 1997;76:F47-50.

19 Jahnukainen T, Ravenswaaij-Arts C, Jalonen J, et al. Dynamics of vasomotor thermoregulation of the skin in term and preterm neonates. Early Hum Dev 1993;33:133-43.

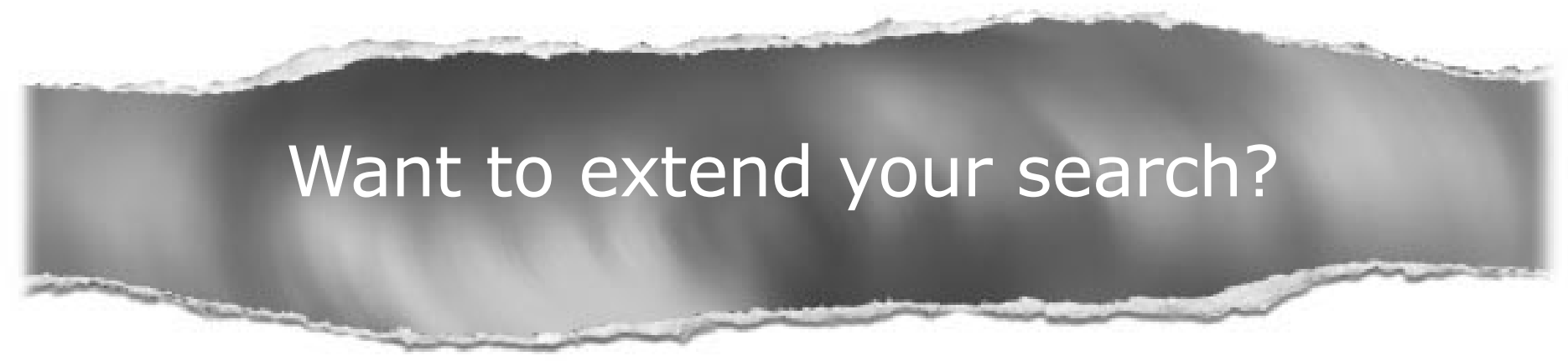

\section{Cross journal searching}

If you can't find what you are looking for in Archives of Disease in Childhood you can extend your search across many of the more than 200 journals available for selection. You can restrict your search to specific subject areas (eg, clinical medicine, basic research), or select specific journals, or search all available titles. 